\title{
Flood Risk Assessments: Applications and Uncertainties
}

\author{
Andrés Díez-Herrero ${ }^{1}$ (D) and Julio Garrote ${ }^{2, *}$ (D) \\ 1 Geological Hazards Division, Geological Survey of Spain (IGME), 28003 Madrid, Spain; andres.diez@igme.es \\ 2 Department of Geodynamics, Stratigraphy and Paleontology, Complutense University of Madrid, \\ 28040 Madrid, Spain \\ * Correspondence: juliog@ucm.es; Tel.: +34-91-394-4850
}

Received: 20 July 2020; Accepted: 22 July 2020; Published: 24 July 2020

\begin{abstract}
The present Special Issue brought together recent research findings in Flood Risk Assessments (FRA) and contains contributions on advanced techniques and real cases where FRA have been carried out. The 16 research contributions highlight various processes and related topics where FRA have been applied and the main benefits and improved knowledge derived from them, as well as their replicability in other study sites. The published papers can be classified into three major categories. (a) First, there are those papers focused on improving the methods and results of FRA over different scenarios of both flooding types (river flooding or flash flooding) and flooding areas (urban, non-urban, small mountain communities). (b) Second, there are studies that investigate the application of FRA to diverse topics such as "land urban planning" or "vulnerable infrastructure management (dams, power plants)". (c) Finally, there is a third group of papers which are focused on the assessment of the sources of uncertainties in FRA, with the aim of improving the results and making it more consistent with the real world.
\end{abstract}

Keywords: flood risk assessment; flood damage uncertainty; flood hazard; flood vulnerability

\section{Introduction}

Flood risk assessment (hereafter abbreviated as FRA) is a scientific/technical subdiscipline or a set of techniques regarding the quantitative analysis and evaluation of flood risk. But subdiscipline includes a notable terminological confusion that is reflected in the titles and contents of the studies, and it conditions the uncertainties and their application to various fields of management. Thus, the first purpose of this editorial introduction should be to clarify terms such as risk, risk analysis and assessment, uncertainty, and the different types of floods that can be evaluated and analyzed.

There are several definitions of 'Risk', from the academic/technical to the popular or common concepts and usages. One of the most accepted technical definitions of 'Risk' is that proposed by the United Nations International Strategy for Disaster Reduction [1]: the combination of the probability of an event and its negative consequences. This definition closely follows the definition of the International Organization for Standardization/International Electrotechnical Commission (ISO/IEC) Guide 73 [2]: "effect of uncertainty on objectives"; this standard definition was subsequently reviewed and confirmed in 2016, and therefore remains current. Many other interesting qualitative definitions have been made by the Society for Risk Analysis (SRA; [3]): (a) Risk is the possibility of an unfortunate occurrence; (b) Risk is the potential for realization of unwanted, negative consequences of an event; (c) Risk is exposure to a proposition (e.g., the occurrence of a loss) which is uncertain; (d) Risk is the consequences of the activity and associated uncertainties; (e) Risk is uncertainty about the severity of the consequences of an activity with respect to something that humans value; (f) Risk is the occurrence of some specified consequence of the activity and associated uncertainties. 
Once again following the SRA glossary [3], 'Risk analysis' is the systematic process of comprehending the nature of risk and expressing risk with the available knowledge; it is often understood in a broader way. Other standards [2] define risk analysis as the process of comprehending the nature of risk and determining the level of same.

On the other hand, according to the Cambridge Advanced Learner's Dictionary, 'assessment' is "the process of considering all the information about a situation or a person and making a judgement". Meanwhile, 'analysis' is "the process of studying or examining something in an organized way to learn more about it, or a particular study of something". Following UN terminology, [1] 'Risk assessment' is a methodology of determining the nature and extent of risk by analyzing potential hazards and evaluating existing conditions of vulnerability that together could potentially harm exposed people, property, services, livelihoods and the environment on which they depend.

For the SRA, 'risk analysis' is defined to include risk assessment, characterization, communication, management, and risk-related policy, in the context of risks of concern to individuals, to public and private sector organizations, and to society at a local, regional, national or global level [3]. Otherwise, according to the ISO [2], risk assessment is the overall process of risk identification, analysis and evaluation. So the main difference between 'assessment' and 'analysis' is that the former implies evaluation and quantification, and not only a qualitative decomposition of a complex element into its components or factors. In summary, risk assessment is a part of risk analysis, comprising the quantitative evaluation of a risk.

Most of the SRA definitions of 'Risk' include the term 'uncertainty' (see aforementioned definitions). This is because most of the processes of risk assessment include uncertainties in computing the components (hazard, exposure, vulnerability), factors (frequency and magnitude) and parameters (e.g., water depth, velocity, energy, sediment load). So uncertainty is an essential item in both risk assessment and analysis.

Finally, the term 'flood' includes several different natural and artificial processes and phenomena, from the inundation of emerged areas by water to coastal flooding; and comprises both large slow river floods and flash floods. There are several classifications of flood types, using different criteria [4]: (i) flood origin (natural vs. anthropic; induced vs. aggravated); (ii) floodable area (inland vs. coast); (iii) floodable media (river vs. sea/lake); (iv) flood dynamics (deluge vs. flash flood), etc. So the correct term for applying risk assessment to floods should be enunciated in the plural: risk assessment of floods.

As a consequence of this terminological complexity, the scientific/technical literature on flood risk assessment and/or analysis is diverse and sometimes confuses its objectives and scope. However, within this multiplicity of approaches, three large sets of typologies of FRA studies can be found: general FRA, including simple flood hazard analysis and integrated analysis; the different fields of application of FRA, from land use and urban planning to emergency management; and the estimation of uncertainties in FRA, their propagation along the analysis process, and reduction mechanisms. These sets will form the organization of the papers and the editorial sections in this special issue.

\section{General Studies of Flood Risk Assessment and Flood Hazard Analysis}

Although studies of FRA have existed for decades, it can be considered an emerging discipline, because scientific/technical production has increased by near two orders of magnitude in the last quarter century, from 13 to more than 850 publications/year (Figure 1). 


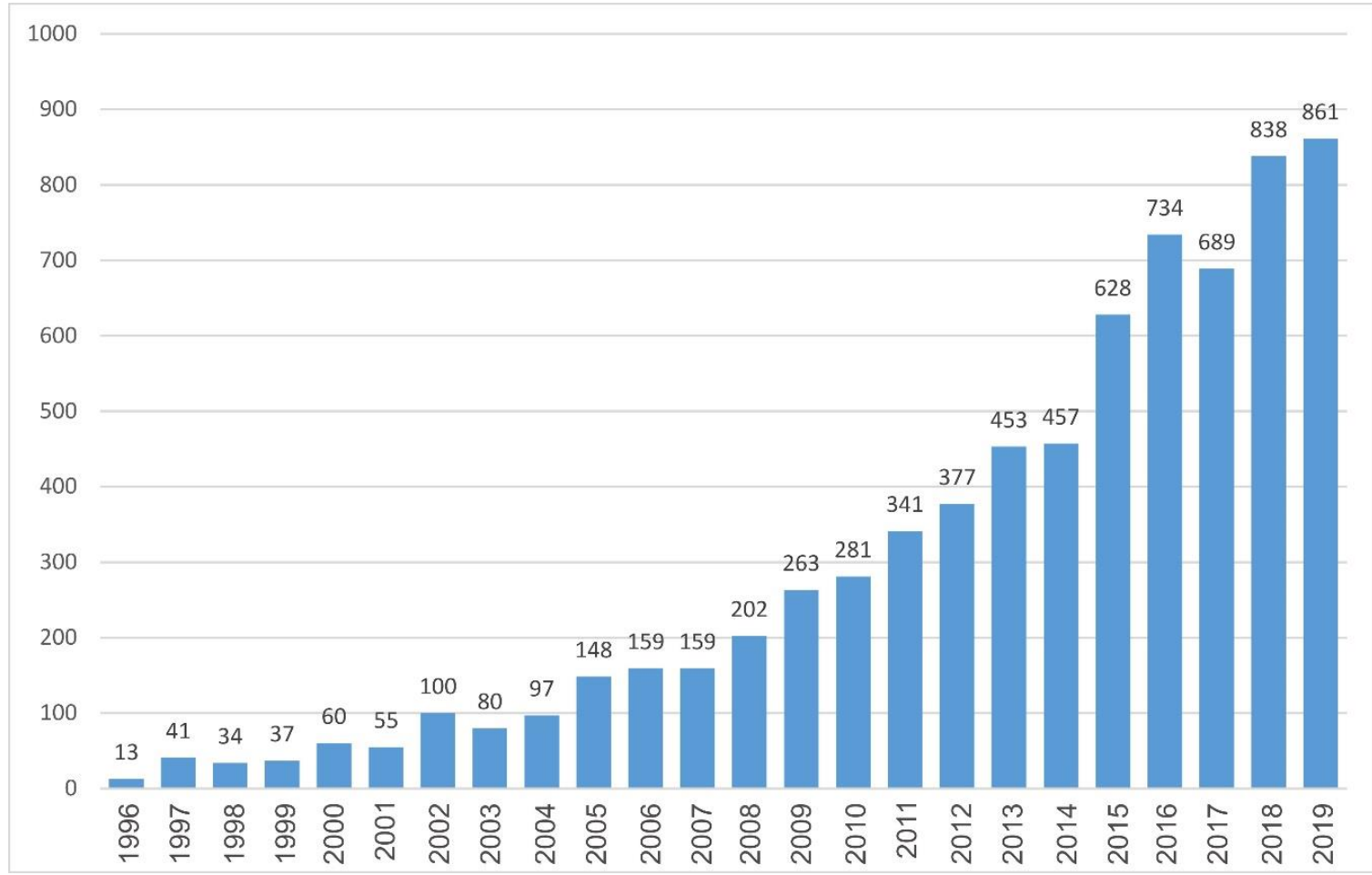

Figure 1. Bar chart of the time evolution of scientific-technical publications (records) on Flood Risk Assessments (FRA) in the Web of Science (WoS) database (search: "flood" AND "risk" AND "assessment"), from 1996 to 2019 [5].

General FRA includes both classical flood hazard analysis (FHA) and integrated true flood risk analysis (FRAn). The former, in turn, includes both flood frequency analysis (FFA: exceedance probability, return period) and magnitude estimates (e.g., discharge, water depth, flow velocity and power, transported solid load, etc.). The second also needs to analyze the exposed elements and their vulnerability (social, economic, environmental, etc.), and the integration of different factors, variables and parameters [6]. But both FHA and FRAn need to use quantitative tools, such as statistics, modeling, or empirical equations, to be true FRAs, because simple qualitative approaches cannot be considered assessments in the strict sense.

This is how the first five papers of this special issue address the topic very differently, but share the idea of the quantification of the hazard or flood risk or its factors (hazard, vulnerability, etc.).

The first addresses one of the fundamental aspects of flood hazard: flood susceptibility or 'floodability', the spatial dimension of flood hazard (flood-prone areas). The authors (Tao Fang et al., all of them from Wuhan University, China) use an advanced statistical approach to flood susceptibility, using a Poisson regression based on eigenvector spatial filtering (ESFPS) for evaluating flood risk (actually, flood susceptibility) in the middle reaches of the Yangtze River in China [7]. They employ a regression analysis to model the relationship between the frequency of alarming flood events observed by hydrological stations and hazard-causing factors from 2005 to 2012. To that end, they have selected and integrated eight factors into a Geographical Information System (GIS) environment for the identification of flood-prone basins, including: elevation (ELE); slope (SLO), elevation standard deviation (ESD); river density (DEN); distance to mainstream (DIST); Normalized Difference Vegetation Index (NDVI); mean annual rainfall (RAIN); mean annual maximum of three-day accumulated precipitation (ACC); and frequency of extreme rainfall (EXE). The results lead us to conclude that elevation, frequency of extreme rainfall, distance to rivers, NDVI and mean annual accumulation of three-day accumulated precipitation are important factors resulting in high flood risk; and ACC and NDVI are the two main factors. This means that the proposed ESFPS model can be used to map flood 
risks throughout basins and new recent data can function as an early warning system and help identify where hydrological stations should be built and strengthened for monitoring the water level.

An important issue in FRA, especially for certain types of floods and multi-hazard approaches, is the inventory of hazardous elements which can potentially damage vulnerable infrastructures. For example, Mei Liu et al. [8] have carried out a glacial lake inventory for the lake outburst flood (GLOF)/debris flow hazard assessment after the Gorkha earthquake in the Bhote Koshi Basin (BKB, China). This glacial lake outburst hazard assessment included two steps, glacial lake outburst potential assessment and flow magnitude assessment. The glacial lake inventory was established, and six unreported GLOF events were identified, with geomorphic outburst evidence from GaoFen-1 satellite images and Google Earth. Four GLOF hazard classes were derived according to glacial lake outburst potential and a flow magnitude assessment matrix, in which 11 glacial lakes were identified to have very high hazard and 24 to have high hazard. They found that the GLOF hazard in BKB increased after the earthquake due to landslide deposits, which increased by $216.03 \times 106 \mathrm{~m}^{3}$, which provides abundant deposits for outburst floods to evolve into debris flows. They suggest that, in regional GLOF hazard assessment, small glacial lakes should not be overlooked for landslide deposit entrainment along a flood route that would increase peak discharge, especially in earthquake-affected areas where large numbers of landslides were triggered.

FRA also serves to check how land use changes can modify flood hazard in terms of frequency and magnitude of extreme events and their associated damages. So Furdada et al. [9] have studied the site of a ski resort at the headwaters that led to the surpassing of a geomorphological threshold, with important consequences during flood events. They considered the interaction of the various controlling factors, including bedrock geology, geomorphological evolution, derived soils and colluvial deposits, rainfall patterns, and the hydrological response of the catchment to flood events. For example, the hydrological results of precipitation-runoff models show a major increase in discharge, reaching up to $26 \%$ for T10 and coinciding with the largest increase in the ski slopes' surface in recent years. Consideration of all the interactions leads them to conclude that a geomorphological threshold has been overcome recently (2006-2008), producing a shift in the torrential dynamics of the basin that turned into very dense, highly erosive sediment-laden flows. Present conditions and projected climate change suggest that current dynamics are likely to continue despite the efforts to stabilize the most active torrent stretches. Closely monitored interventions in the headwaters should be carried out, particularly focusing on re-vegetation.

Most FRAs usually forget to analyze one of the most important components of integrated flood risk: vulnerability. When vulnerability is analyzed, only economic vulnerability is usually included [6], and the social or environmental modalities of vulnerability are forgotten. Accordingly, studies such as the one carried out by Ferrer et al. [10], focusing on social flood vulnerability assessment in the municipality of Ponferrada (Spain), are interesting and necessary. They propose a methodology for the analysis of social vulnerability to floods based on the integration and weighting of a range of exposure and resistance (coping capacity) indicators. This needs selection and characteristics of each proposed indicator and an integration procedure based on a large-scale analytic hierarchy process (AHP). Detailed mapping of the social vulnerability index is generated at the urban land-parcel scale. It concluded that almost $77 \%$ of the affected population of Ponferrada (34,941 inhabitants) will not be able to reach a safe place, because a time to evacuate of at least $15 \mathrm{~min}$ is required (timespan for the water wave to reach the town). The majority of data used for the calculation of the indicators comes from open public data sources, which allows the replicability of the method in any area where the same data are available.

Finally, one of the most widely used approaches of FRAs is the quantitative estimation of future flood damages both from a social and an economic point of view. Regarding this integrated potential damage assessment, this special issue includes the paper written by Martínez-Gomariz et al., entitled "Socio-Economic Potential Impacts Due to Urban Pluvial Floods in Badalona (Spain) in a Context of Climate Change" [11]. The assessment has a twofold target: people's safety, based on 
both pedestrian and vehicle stability, and impacts on the economic sector in terms of direct damages to properties and vehicles; and indirect damages due to business interruption; all these are related to different return periods (i.e., 2, 10, 100, and 500 years). The main novelties of this paper are the integration of a detailed 1D/2D urban drainage model with multiple risk criteria; and the assessment of flood damages for projected future rainfall conditions (climate change scenarios, such as RCP 8.5) which enabled a comparison to be made with the current conditions, thereby estimating their potential increment. The total Expected Annual Damage (EAD) for Badalona city, considering an estimate of both direct and indirect damages, includes the breakdown of estimated damages for current (1.48 M€) and future rainfall conditions (1.93 M€), a predicted increase due to climate change of $30 \%$ in terms of EAD.

\section{A Wide Range of Applications for Flood Risk Assessment}

Apart from the studies dealing with general Flood Risk Assessment (FRA), a second group of manuscripts are focused on specific applications of FRA (Figure 2), from a global to a regional and local scale, and from levee structure resistance to cultural heritage risk analysis or local flood monitoring from remote sensing data. FRA application studies have not been scarce since the first years of the last century, so the volume of manuscripts range from approximately 200 in the first decade of the twenty-first century to more than a thousand manuscripts per year in the past five years. It is clear from Figure 2 that the most popular FRA application is related to planning tasks, and how resilience analyses have significantly increased in number in recent years.

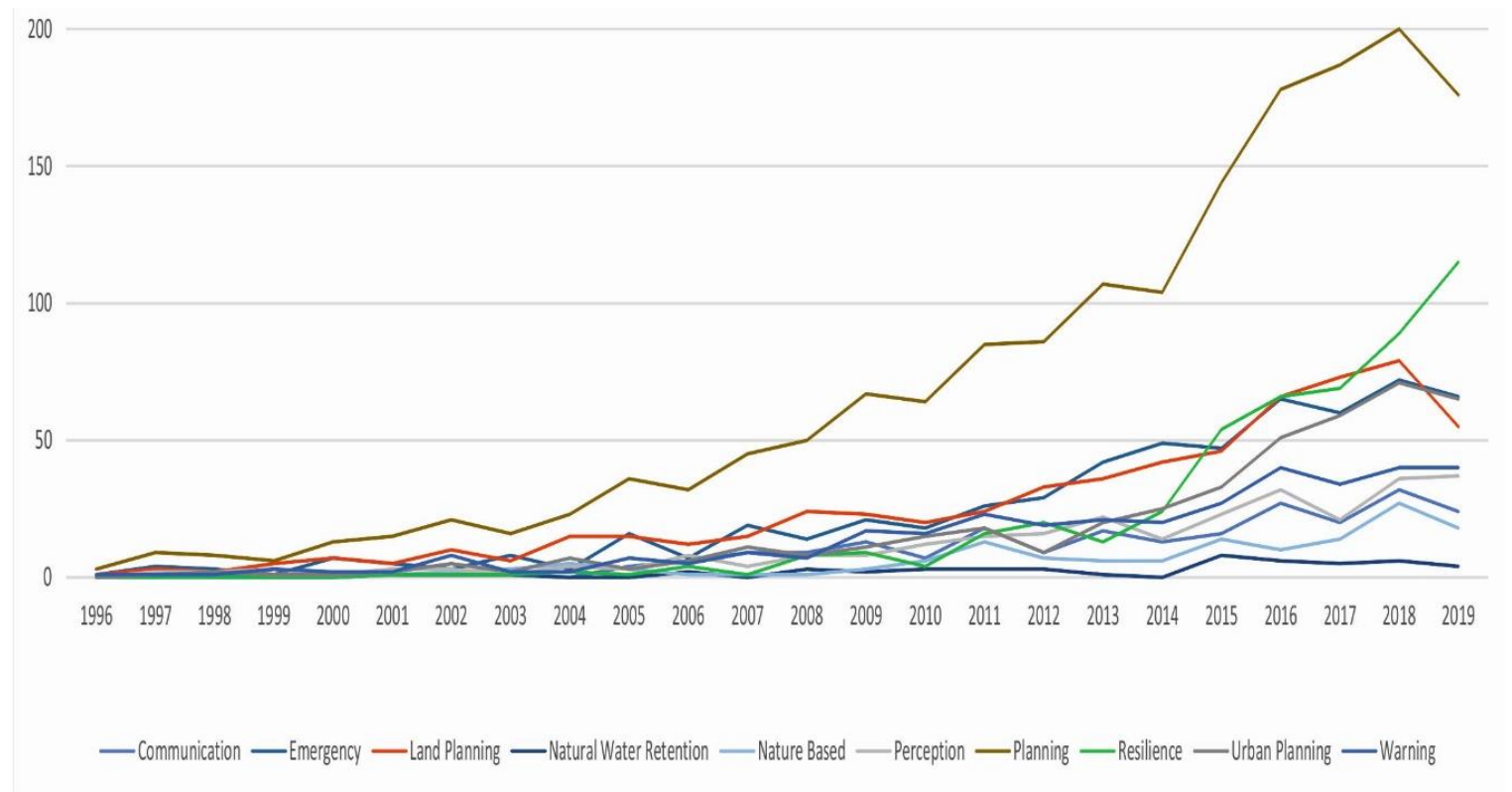

Figure 2. Temporal evolution of scientific/technical publications (records) on the main fields of application of FRA in the WOS database (search: "flood" AND "risk" AND "assessment" BY (fields of application)), from 1996 to 2019 [5].

The most globally focused research is that of Özer et al. [12], who have collected information and developed a global database on levees as fluvial defense, the International Levee Performance Database (ILPD), which aims to become a valuable knowledge platform in the field of levee safety. The ILPD comprises information on levee characteristics, failure mechanisms, geotechnical investigations and breach processes for more than 1500 cases. From all these data, the authors have extracted key conclusions, as external erosion is identified as the most frequent process for levee failures. The manuscript shows that initial failure mechanisms have an influence on breach characteristics and that failures due to instability and internal erosion are less frequent but lead to larger breaches. 
Moreover, a relationship between the return period and the expected breach density during a flood event is identified, so flood events with a return period higher than 200 years produce a significant increment in breach density. Furthermore, external erosion is more likely to occur for high return periods. All these data and conclusions, in combination with hydraulic/geotechnical models, could eventually be used to complement risk assessments and to design more robust and resilient flood defenses, with less probability of catastrophic breaching.

Following with the effects of flooding on structures, Pérez-Morales et al. [13] focused their assessment on transport network vulnerability to floods. From their analysis, an optimum location of Emergency Management Centers could be derived, combined with the probable worsening of these relationships due to the effects of climate change or global warming. Given such circumstances, analysis of the vulnerability of transportation networks is a technique whose results highlight deficiencies and serve as support for future decisions concerning the transformation of the network or the installation of new emergency centers. Two main results could be highlighted from the assessment: (a) a map of present network vulnerability informs us of critical network sections that should be reinforced or protected to facilitate evacuation of the population and the movement of emergency teams in case of catastrophe; (b) when these adaptation measures are not to be carried out, solutions like finding the optimum location for a new Emergency Management Center based on reduced travel time to reach the rescue points could be the best to fill that gap. The results obtained could be used in urban planning tasks to improve the resilience of urban areas against an increase in flood episodes caused by climate change.

Garrote et al. [14] focused their application of FRA on another type of structure, which cannot usually be classified into tangible or intangible elements. These elements, such as cultural heritage (archaeological sites, historical buildings, artworks, etc.) are often located somewhere between both categories. This means they can be assigned an economic value (market value), while at the same time they represent the record of the history of human civilization, whose value is intangible. The application of FRA to cultural heritage is based on the implementation of three proposed matrices (flood hazard, flood vulnerability, and potential flood risk) in a GIS environment, which allows the estimation of the flood risk level presented by the cultural heritage elements and their classification. The flood hazard matrix uses variables such as flow depth, return period (years) and flood type (river flood or flash flood). The flood vulnerability matrix is constructed on three groups of variables (materials vulnerability, structural vulnerability, and specific content vulnerability). The qualitative characterization of the potential flood risk for the heritage site and its spatial distribution, both direct results of the methodological framework proposed here, can and should serve as a key tool for cultural heritage managers at a city, region, or state administrative level.

From the various FRA applications to different types of structures, Carreño Conde and De Mata Muñoz [15] show the applicability of Sentinel-1 Synthetic Aperture Radar (SAR) images for flooding area monitoring on a flood event scale. The authors show from their analysis that the best results from the final flood mapping for the study area were obtained using VH (Vertical-Horizontal) polarization configuration and Lee filtering $7 \times 7$ window sizes. Using pre- and post-event images with the Red-Green-Blue (RGB) method they obtained highlights of the non-permanent water bodies. The authors calibrate results in two ways: (a) comparing the flood maps obtained with the flood areas digitalized from vertical aerial photographs planned by the Hydrological Planning of the Ebro Hydrographic Confederation; and (b) comparing the results with maps of different return periods for flooded areas provided by the National Flood Zone Mapping System in Spain. The consensus between these different data sources confirmed and validated the use of Sentinel-1 SAR images to obtain flood maps with the required accuracy, and point out that they can be used as a new source of input, calibration, and validation for hydrological models to improve the accuracy of flood risk maps.

Related to the previous manuscript, Menéndez Pidal et al. [16] study and prove the effectiveness of real time integrated data provision from the Automatic Hydrological Information System (SAIH) of the Tagus River (including snow accumulation/melting processes and the forecast of inflows to the reservoir 
to help in the establishment of safeguards and preventive water flow releases). As an application study site of their FRA, the methodology described is shown in a real case at Rosarito and El Burguillo Reservoirs. In these two reservoirs, located in the upper mountainous part of the basin, the authors show the improvement in inflow and outflow management derived from their methodological approach which translates into an improvement in risk management against flood hazards downstream of the location of both reservoirs.

Using another specific data source, i.e., tree-ring evidence, Franco-Ramos et al. [17] carried out an assessment of lahar activity at the Pico de Orizaba Volcano (Mexico) using the debris-flow module of the rapid mass movement simulation tool RAMMS on a highly resolved digital terrain model obtained with an unmanned aerial vehicle. They use the scars found in 19 Pinus hartwegii trees (that served as paleo-stage indicators, PSI) to calibrate a model reconstructing the 2012 event magnitude. Using this combined assessment and calibration of RAMMS, the authors obtain a peak discharge of $78 \mathrm{~m}^{3} \mathrm{~s}^{-1}$ for the 2012 lahar event which was likely to have been triggered by torrential rainfall during hurricane "Ernesto". Results also show that the deviation between the modeled lahar stage (depth) and the height of PSI in trees was up to $\pm 0.43 \mathrm{~m}$. These deviations are not evenly distributed spatially, as the authors show, and they are in some way related to the formation energy of landforms. The largest deviations are located on cut banks and/or in straight and exposed positions, and moderate and smaller deviations were typically found in intermediate and low-energy landforms, such as alluvial terraces. The research is another example $[18,19]$ of the usefulness of tree-ring evidence as a data source for hydrodynamic modeling calibration and improvement of FRA.

Finally, the research of Špitalar et al. [20] entitled "Analysis of Flood Fatalities-Slovenian Illustration" constitutes the sixth and last manuscript included in this second group of research papers focused on applications of FRA. In Slovenia, they assessed the influence of different factors external to the hazard of flooding on the gravity and extent of the impact in a historical analysis (1926-2014), which includes up to 10 flooding events (from a complete record of 21 severe floods) that induced 74 casualties. Their results highlight the increasing trend in recent years of victims in cars in rural areas. From these results, an adult or elderly male is the most vulnerable to flooding effects. Focusing on demographic aspects (age and gender) of fatalities and an analysis of the circumstances of loss of life, different groups were established based on the type of flood fatality. From all these groups, victims related to the collapse of both buildings and structural mitigation measures are the most common. Evaluations of results have also shown an increasing need for improvements in communication strategies between fire fighters and the Administration of the Republic of Slovenia for civil protection and disaster relief. The assessment gives an overview of demographic, temporal and circumstantial aspects of victims, at the same time as it improves knowledge about mitigation and preventative measures that can be taken in the future and about the remaining challenges regarding how to reduce social vulnerability to flooding.

\section{Uncertainties in Flood Risk Assessment}

The third group of research is focused on uncertainty analysis concerning FRA (Figure 3). This last group is the one composed of a smaller number of three manuscripts. Uncertainty analyses of FRA have become more recurrent in the past decade, when the number of manuscripts has increased from a couple of dozen to more than a hundred in the last five years. This increase points towards a major idea: it is not only now necessary to perform FRA studies, but it has also become necessary to analyze their quality and the degree of trust that we can place in them, all this from the point of view of the applicability of these studies to the real world. It is clear that the volume of uncertainty analyses is lower than other topics related to FRA, and this is an area of study that still requires further scientific attention. 


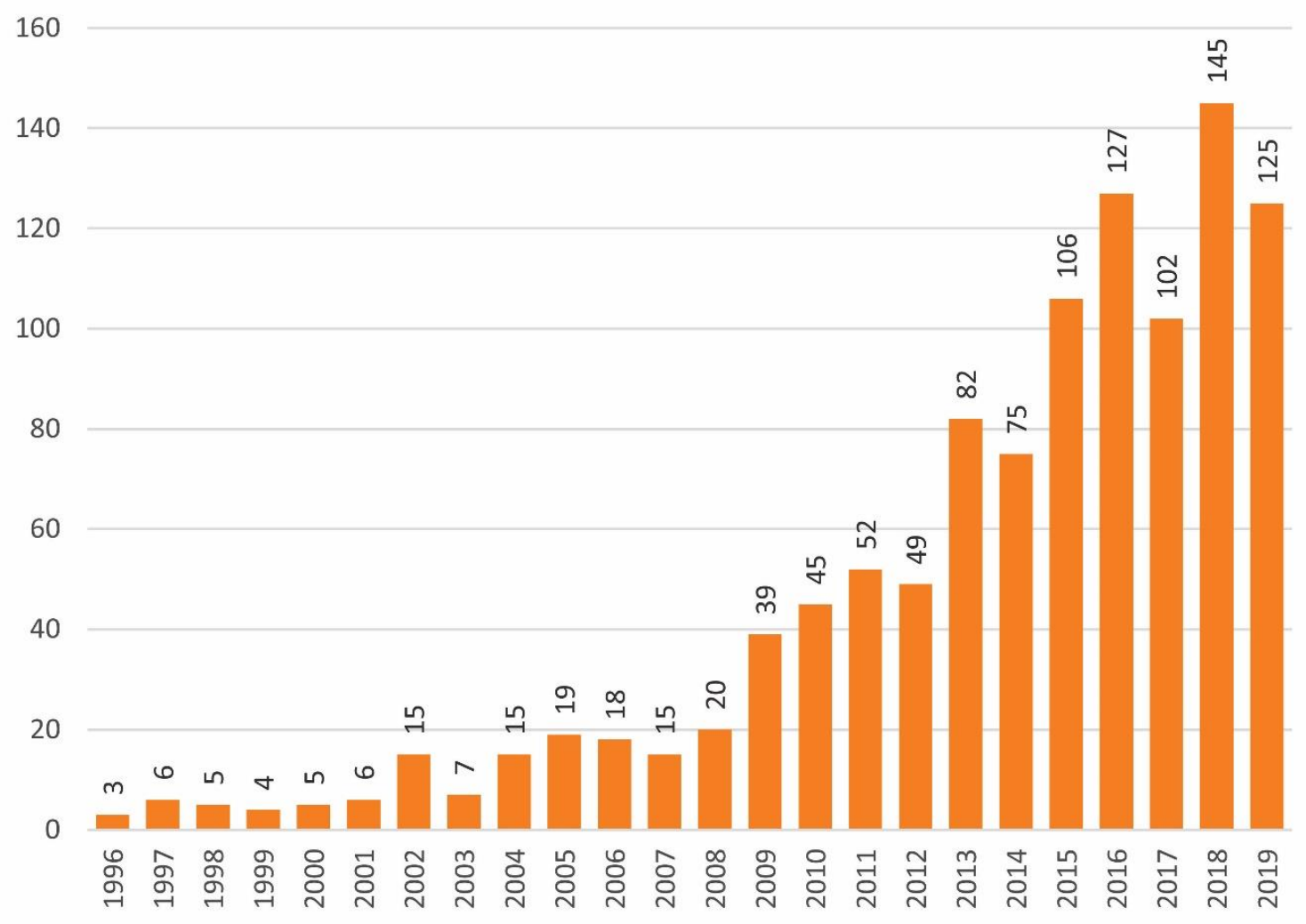

Figure 3. Bar chart of the time evolution of scientific/technical publications (records) on uncertainties in FRA in the WOS database (search: "flood" AND "risk" AND "assessment" AND "uncertainty*"), from 1996 to 2019 [5].

In the first, Garrote et al. [21] make a type of uncertainty assessment about results of meso- or macro-scale FRA (developed by combining Fuzzy DELPHI, MCA, and GIS techniques) from the use of phone calls to Emergency Services (112). In recent years, the use of social network data for flood hazards, risk analyses and calibration processes are increasing, although use of data from social networks also has its drawbacks, such as the biases associated with age and gender, and their spatial distribution. As the authors show, some of these biases can be resolved by calls made to Emergency Services, although other problems are still latent. For example, a bias does exist in the relationship between the size of the population and the number of calls made to Emergency Services. The use of data from calls made to Emergency Services and local regression models such as LOESS (locally estimated scatterplot smoothing) allowed the authors to establish the correct relationship between categorized potential risk levels (from usual FRA) and the inferred potential risk (obtained from data from Emergency Services). Therefore, based on the number of calls made to Emergency Services, we can categorize those municipalities that should be the subject of a more detailed study and those whose classification should be revised in future updates.

The research of Lastrada et al. [22] makes another kind of uncertainty assessment related to future projections of FRA under climate change scenarios (global warming). The main objective of the paper is to present a methodology to estimate climate change effect on flood hazard and flood risk using different climate models regarding a scenario of comparatively high greenhouse gas emissions (RCP 8.5). From daily temperature and precipitation data (from 2007 to 2070), and comparing results in relative terms, flow rate and flood risk variation due to climate change are estimated. In the specific case of the study site, the Meteorological Research Institute (MRI)- Coupled Global Climate Model (CGCM3) model (obtained from Spanish Meteorological Agency website for RCP 8.5) shows that climate change will cause a significant increase of potential affected inhabitants and economic damage 
due to flood risk. Due to the large uncertainty in climate projections that influences the estimation of future flood risk, the crucial action for authors in the case of adaptation to floods is to carry out a detailed analysis to choose the best climate model and use results in relative terms between short term (first stage) and long term (second stage) of the projection period. This evaluation enables the definition of mitigation actions in terms of cost benefit analysis and prioritization of those that should be included in Flood Risk Management Plans.

The last work, by Garrote and Bernal [23], investigated the uncertainty in FRA regarding the consideration or not of the topographic ( $Z$ value) difference between the main floor of houses and the surrounding land. To carry out this analysis, up to a total of 28 magnitude-damage functions (with different characteristics and application scales) were selected on which the effect of over-elevation and under-elevation of the main floor of the houses was simulated (at intervals of $20 \mathrm{~cm}$, between -0.6 and $+1 \mathrm{~m}$ ). Each topographic configuration (over- or under-elevation) causes overestimation or underestimation of flood damage. Possible errors in economic quantification of flood damages are maximized for low flow depth values and became constant when flow depth rose to values higher than 1.5-2 m. Out of the theoretical assessment of the effects on magnitude-damage models, the authors use a real scenario where the consideration of this variable (as opposed to its non-consideration) causes an average variation in the damage estimation of around $30 \%(22.5 \%$ of reduction in EAD when over-elevation of main floor is considered in FRA). So, from these results, the analyzed variable can be considered as (1) another main source of uncertainty in the correct estimation of flood damage, and (2) an essential variable to take into account in a flood damage analysis for the correct estimation of loss.

Finally, a review manuscript by Guest Editors of this Special Issue, Díez-Herrero and Garrote [24] entitled "Flood Risk Analysis and Assessment, Applications and Uncertainties: A Bibliometric Review" completes this volume. The authors, through a bibliometric analysis of the most popular and complete scientific databases (Web of Science (WoS)), show us the range of flood risk analysis and assessment over time and around the world, comprising all the scientific and technical literature included in WoS. This approach may be the only way to understand the temporal and spatial evolution of this sub-discipline which interprets the emerging fields of applications and the main sources of uncertainty, overcoming limitations (in the opinion of the authors) of most other thematic reviews, which show a snapshot or a partial point of view of FRAs, focused on only a small number of selected methods and approaches. For the authors, there are four themes within FRA research that mark future trends: global change, coastal floods, economic evaluation, and psycho-social analysis of floods.

\section{Conclusions}

In conclusion, this special issue contains 16 studies with important results, covering several aspects of Flood Risk Assessment, from those focused on improving the methods and results of FRA over different scenarios of both flooding types (river flooding or flash flooding) and flooding areas (urban, non-urban, small mountain communities), to studies focused on the analysis of uncertainties in FRA results. While it is true that most studies focus on examples of the main FRA applications, three studies focus on the assessment of different structures (from levees to cultural heritage elements).

Author Contributions: A.D.-H. and J.G. have both conceived the idea and wrote the manuscript. All authors have read and agreed to the published version of the manuscript.

Funding: The guest editorial works have been funded by the research project DRAINAGE, CGL2017-83546-C3-R (MINEICO/AEI/FEDER, UE); and it is specifically part of the outreach work packages and dissemination tasks carried out under the coverage of the sub-project DRAINAGE-3-R (CGL2017-83546-C3-3-R; MINEICO/AEI/FEDER, UE).

Acknowledgments: Guest editors thank all the authors of the published papers, manuscripts reviewers and assistant editors for the great support to the realization of the present special issue.

Conflicts of Interest: The authors declare no conflict of interest. 


\section{References}

1. UNISDR. UNISDR Terminology on Disaster Risk Reduction; United Nations International Strategy for Disaster Reduction (UNISDR), United Nations (UN): Geneva, Switzerland, 2009; p. 35. Available online: https: //www.unisdr.org/publications (accessed on 17 January 2020).

2. ISO. ISO GUIDE 73:2009, Risk Management-Vocabulary; International Organization for Standardization (ISO): Vernier, Switzerland, 2009; p. 15.

3. Aven, T. Society for Risk Analysis Glossary; Committee on Foundations of Risk Analysis, Society for Risk Analysis (SRA): McLean, VA, USA, 2015; p. 15.

4. Díez-Herrero, A.; Lain-Huerta, L.; Llorente-Isidro, M.A. Handbook on Flood Hazard Mapping Methodologies, 1st ed.; Series Geological Hazards /Geotechnics, No. 2; Geological Survey of Spain (IGME): Madrid, Spain, 2009; p. 190.

5. Web of Science Database (WOS). All Databases; Clarivate Analytics. Available online: https://apps. webofknowledge.com/ (accessed on 17 March 2020).

6. Merz, B.; Kreibich, H.; Schwarze, R.; Thieken, A. Assessment of economic flood damage: Review article. Nat. Hazards Earth Syst. Sci. 2010, 10, 1697-1724. [CrossRef]

7. Fang, T.; Chen, Y.; Tan, H.; Cao, J.; Liao, J.; Huang, L. Flood risk evaluation in the middle reaches of the Yangtze River based on eigenvector spatial filtering poisson regression. Water 2019, 11, 1969. [CrossRef]

8. Liu, M.; Chen, N.; Zhang, Y.; Deng, M. Glacial lake inventory and lake outburst flood/debris flow hazard assessment after the Gorkha earthquake in the Bhote Koshi Basin. Water 2020, 12, 464. [CrossRef]

9. Furdada, G.; Victoriano, A.; Díez-Herrero, A.; Génova, M.; Guinau, M.; De las Heras, A.; Palau, R.M.; Hürlimann, M.; Khazaradze, G.; Casas, J.M.; et al. Flood consequences of land-use changes at a ski resort: Overcoming a geomorphological threshold (Portainé, Eastern Pyrenees, Iberian Peninsula). Water 2020, 12, 368. [CrossRef]

10. Tascón-González, L.; Ferrer-Julià, M.; Ruiz, M.; García-Meléndez, E. Social vulnerability assessment for flood risk analysis. Water 2020, 12, 558. [CrossRef]

11. Martínez-Gomariz, E.; Locatelli, L.; Guerrero, M.; Russo, B.; Martínez, M. Socio-economic potential impacts due to urban pluvial floods in Badalona (Spain) in a context of climate change. Water 2019, 11, 2658. [CrossRef]

12. Özer, I.; van Damme, M.; Jonkman, S. Towards an International Levee Performance Database (ILPD) and its use for macro-scale analysis of levee breaches and failures. Water 2020, 12, 119. [CrossRef]

13. Pérez-Morales, A.; Gomariz-Castillo, F.; Pardo-Zaragoza, P. Vulnerability of transport networks to multi-scenario flooding and optimum location of emergency management centers. Water 2019, 11, 1197. [CrossRef]

14. Garrote, J.; Díez-Herrero, A.; Escudero, C.; García, I. A framework proposal for regional-scale flood-risk assessment of cultural heritage sites and application to the Castile and León Region (Central Spain). Water 2020, 12, 329. [CrossRef]

15. Carreño Conde, F.; De Mata Muñoz, M. Flood monitoring based on the study of Sentinel-1 SAR images: The Ebro River case study. Water 2019, 11, 2454. [CrossRef]

16. Menéndez Pidal, I.; Hinojal Martín, J.A.; Mora Alonso-Muñoyerro, J.; Sanz Pérez, E. Real-time data and flood forecasting in Tagus Basin. A case study: Rosarito and El Burguillo reservoirs from 8th to 12th March, 2018. Water 2020, 12, 1004. [CrossRef]

17. Franco-Ramos, O.; Ballesteros-Cánovas, J.; Figueroa-García, J.; Vázquez-Selem, L.; Stoffel, M.; Caballero, L. Modelling the 2012 lahar in a sector of Jamapa Gorge (Pico de Orizaba Volcano, Mexico) using RAMMS and Tree-Ring evidence. Water 2020, 12, 333. [CrossRef]

18. Ballesteros Cánovas, J.A.; Bodoque, J.M.; Díez-Herrero, A.; Sanchez-Silva, M.; Stoffel, M. Calibration of floodplain roughness and estimation of palaeoflood discharge based on tree-ring evidence and hydraulic modelling. J. Hydrol. 2011, 403, 103-115. [CrossRef]

19. Garrote, J.; Díez-Herrero, A.; Génova, M.; Bodoque, J.M.; Perucha, M.A.; Mayer, P.L. Improving flood maps in ungauged fluvial basins with dendrogeomorphological data. An example from the Caldera de Taburiente National Park (Canary Islands, Spain). Geosciences 2018, 8, 300. [CrossRef]

20. Špitalar, M.; Brilly, M.; Kos, D.; Žiberna, A. Analysis of flood fatalities-Slovenian illustration. Water 2020, 12, 64. [CrossRef] 
21. Garrote, J.; Gutiérrez-Pérez, I.; Díez-Herrero, A. Can the quality of the potential flood risk maps be evaluated? A case study of the social risks of floods in Central Spain. Water 2019, 11, 1284. [CrossRef]

22. Lastrada, E.; Cobos, G.; Torrijo, F.J. Analysis of climate change effect on flood risk. Case study of reinosa in the Ebro river basin. Water 2020, 12, 1114. [CrossRef]

23. Garrote, J.; Bernal, N. On the influence of the main floor layout of buildings in economic flood risk Assessment: Results from Central Spain. Water 2020, 12, 670. [CrossRef]

24. Díez-Herrero, A.; Garrote, J. Flood risk analysis and assessment, applications and uncertainties: A bibliometric review. Water 2020, 12, 2050. [CrossRef]

(C) 2020 by the authors. Licensee MDPI, Basel, Switzerland. This article is an open access article distributed under the terms and conditions of the Creative Commons Attribution (CC BY) license (http://creativecommons.org/licenses/by/4.0/). 